\title{
REGION, powered by WU
}

\author{
Christoph Badelt ${ }^{1}$, Rector of WU \\ ${ }^{1}$ WU, Vienna University of Economics and Business, Vienna, Austria (email: christoph.badelt@wu.ac.at)
}

Received: 21 July 2014/Accepted: 21 July 2014

WU, the Vienna University of Economics and Business, is proud to collaborate with ERSA in publishing the new open access journal, REGION. We host the respective server, manage the software installation, and provide technical and administrative support. A generous grant from the Austrian Science Fund (FWF) has allowed us to develop the necessary infrastructure and to implement with REGION a "diamond" version of open access, meaning it is free of charge for authors as well as for readers.

The cooperation between WU and ERSA establishes a clear win-win-situation: such cooperation between a large scientific association and a large university will give enough academic reputation and organizational power to REGION so that it can develop into an important and globally competitive publication outlet in regional science. As the largest business university in Europe, WU provides a stable organizational framework and institutional credibility. WU hosts this new journal and contributes technical assistance via IT and library services. For WU, this initiative offers the opportunity to strengthen its position as an internationally recognized research university, and as an important center of regional science in Europe. From a broader perspective, WU sees REGION as an opportunity to develop competence and infrastructure for a greater support of open access in the near future. With the success of REGION, we will be able to convince other journal publishers to go (diamond) open access and to utilize the infrastructure we have developed with REGION. This will boost open access in the areas of business and economics that WU stands for.

The establishment of REGION and of the corresponding publishing infrastructure contributes to the principle of sustainability, as stated in WU's development plan. A sustainable university implies more than green buildings - WU moved to a DGNBcertified new campus in 2013 - and integrating sustainability issues into research and teaching, as we have done in recent years. A sustainable university also has to reflect on the sustainability of basic academic procedures and act where it identifies problems; academic publishing is one such problem area.

Access to scientific knowledge has become increasingly expensive in recent decades, as university administrators know from their library budgets. The implied financial barriers hamper the exchange of knowledge, scientific progress, and development. By making high quality research freely available over the Internet, we attempt to help reestablish the classical view of research results being a public good. Moreover, since high quality research originates not only in universities that can afford high publishing fees, we support the "diamond" version of open access that REGION implements.

These are the reasons why REGION is "powered by WU". We wish the journal success, enthusiastic readers and authors, and hope that it will be able to realize its ambitious goals. 